\title{
Bone mineral: update on chemical composition and structure
}

\author{
C. Rey ${ }^{1}$, C. Combes ${ }^{1}$, C. Drouet ${ }^{1}$, and M.J. Glimcher ${ }^{2}$ \\ ${ }^{1}$ University of Toulouse, CIRIMAT, ENSIACET, 118, route de Narbonne, 31077 Toulouse Cedex \\ 04, France \\ 2Laboratory for the Study of Skeletal Disorders and Rehabilitation, Department of Orthopaedic \\ Surgery, Harvard Medical School and Children's Hospital, Boston, Massachusetts, 02115, USA
}

\author{
Keywords \\ Apatites; Ca-P solid phase; X-Ray diffraction
}

\section{History}

The structure of the Ca-P solid phase in bone was first identified by deJong in 1926 as a crystalline calcium phosphate similar to geological apatite by chemical analyses and, most importantly, by X-ray diffraction [1]. The X-ray diffraction data was confirmed a few years later [2].

These findings initiated a flurry of research on a more detailed chemical composition and crystal structure of both geological and synthetic apatites and of bone mineral, initially carried out principally by geologists, crystallographers and chemists, but later by biochemists and physiologists because of the clear potential of this new information to shed light on the biological and physiological functions of bone mineral and as indicators of disorders of the skeletal system.

It soon became clear that there were significant structural and chemical compositional differences between the many different geological hydroxyapatites, synthetic hydroxyapatites, and the apatite crystals found in bone and related skeletal tissues in addition to the very large size of the geological and many of the synthetic apatite crystals, compared with the extremely small particle size of bone mineral.

Further studies were directed in roughly three avenues: continued more careful and complete analytical compositional data of bone mineral, from which it was clearly established that the chemical composition of bone crystals in many ways did not correspond to the chemical compositions of stoichiometric hydroxyapatite. Indeed, the bone crystals were found to contain significant and varying amounts of carbonate and $\mathrm{HPO}_{4}$ ions. Much later it was discovered by a variety of techniques, including solid state NMR [3], Raman spectroscopy [4], and inelastic

Corresponding Author: Melvin J. Glimcher, MD, Director, Laboratory for the Study of Skeletal Disorders and Rehabilitation, Harvard Medical School and Children's Hospital, 300 Longwood Ave, Boston, MA 02115, Email: melvin.glimcher@ childrens.harvard.edu, Tel: 617-919-2038, Fax: 617-730-0122.

Christian Rey, CIRIMAT-ENSIACET, 118, route de Narbonne, 31077 Toulouse, Cedex 4, France, Email: Christian.Rey@ensiacet.fr, Tel: 3356288 5635, Fax: 335628857730

Data presented at the Third Meeting on Bone Quality, France, 24-25 June 2008: Bone Ultrastructure

Conflicts of Interest: None 
neutron scattering [5], that the biological bone apatites contain only a very small percentage of the total number of hydroxyl groups present stoichiometric hydroxyapatites.

Other studies clearly pointed out that a substantial fraction of the phosphate ions are situated on the surfaces of the bone mineral crystals and are mainly protonated and in a disordered environment [6], in contrast to the phosphate ions in lattice positions, which are unprotonated. Also, other uniquely protonated phosphate ions were identified in bone mineral by phosphorus 31 NMR spectroscopy which are not present in synthetic calcium phosphate apatites [7].

Structural studies were first carried out to determine crystal size by measuring the extent of Xray diffraction peak broadening [8], which yielded crystal sizes varying from $31 \AA$ to $290 \AA$. More detailed structural data were obtained by the then recently introduced field of electron microscopy and electron diffraction [9-11], which revealed that the bone crystals were thin plates, approximately $500 \AA$ long, $250 \AA$ wide, and $100 \AA$ thick. However, calculations from low angle X-Ray diffraction scattering studies [12-14] were more consistent with the conclusions that the bone crystals were very much smaller than those observed by Robinson et al by TEM, which were rods $250 \AA$ long and $50 \AA$ thick rods and not platelets. Crystal perfection, another structural property of the individual bone nanocrystals is also a function of the extent of mineralization, as demonstrated by the changes in their wide-angle X-ray diffraction patterns [15] [Figure 1].

More accurate evaluations of the size and shape of the bone crystals were later obtained by the development of techniques which removed essentially all of the organic matrix constituents of the bone samples prior to TEM without altering the bone crystals, thus permitting their examination by high resolution TEM and electron diffraction as well as 3D stereoscopic TEM, which firmly established that the bone apatite crystals were indeed nanosized, very thin, long platelets (nanocrystals) and not rods [16-18,]. This was further confirmed by atomic force microscopy $[19,20]$. Further TEM compositional studies of the bone crystals from a wide variety of species as a function of "crystal age"(vide infra) revealed that the initial Ca-P solid phase deposited consisted of irregular, roughly round electron dense particles, some as small as $\sim 10 \AA$ [21]. These data focused attention on the important physiological implications of the enormous surface area of the bone nanocrystals, especially during the early stages of new bone formation and calcification, and its role in ion homeostasis of the extracellular fluids. These data demonstrate another important structural and physical chemical characteristic of the bone crystals as a function of "crystal age" (vide infra), further complicating the problem of quantitatively describing the bone crystals in a particular sample of bone substance.

Great strides have been made in utilizing in vitro calcification experiments using purified native collagen fibrils and metastable solutions of $\mathrm{Ca}$ and $\mathrm{P}$ to gain information on the composition and structure of the initial Ca-P solid phase formed during heterogeneous nucleation. These have demonstrated that purified natively 3D-packed collagen molecules in collagen fibrils with an axial period of approximately $670 \AA$ are capable of heterogeneously nucleating apatite crystals in vitro [22-24].

It was hoped that this information on the potential chemistry and structure of the initial nucleation sites within the collagen fibril responsible for initiating crystallization might be obtained from the in vitro nucleation experiments.

The chemical and X-ray diffraction data identifying the nanocrystals nucleated in vitro by collagen fibrils, including the specific location of the nanocrystals in an orderly repeating pattern within the collagen fibrils [25-27], was later confirmed by wide and low angle X-ray diffraction studies [28]. Much more quantitative in vitro nucleation experiments were carried out by Katz [29], who quantitatively measured the kinetics of in vitro calcification of native collagen fibrils and established the size of the apatite nuclei found in his in vitro nucleation 
studies ( 20 ions under the specific conditions of his experiments). Various schema and experiments were devised from these in vitro studies of nucleation of the likely composition of the nuclei (first solid phase $\mathrm{Ca}-\mathrm{P}$ formed during in vitro calcification) and the potential role of the phosphoryl groups and glutamic acid side chains of a particular noncollagenous matrix protein in bone (bone sialoprotein-BSP) [27,29,30,32].

Very importantly, solid state ${ }^{31} \mathrm{P}$ NMR analysis of the youngest sample of native bone available at that time identified for the first time, the presence of a seryl phosphate-calcium bond, presumably directly linking a prominent protein in the organic matrix of bone (BSP) with the mineral phase [33].

A number of other experiments were also devised and carried out to surmount the problems of how to isolate the very youngest bone mineral crystals in specimens of bone without introducing any contact of the specimens with water, which not only very rapidly dissolves the crystals, but also introduces physical and chemical compositional changes in the crystals which remain in the bone sample.

While the chemical composition and crystal structure, particle size, degree of crystallinity, etc., of the individual bone crystals in a specific sample of bone in a particular location of a particular bone is clearly a significant function of the age of the animal, a recently introduced new concept has pointed out that the most significant "time function" as far as it affects all of the compositional, structural, and interaction properties and characteristics of bone apatite crystals is not the age of the animal, but the age of the individual crystals ("crystal age") viz., the elapsed time between the initial deposition of the crystals and their removal (resorbtion) from the tissue [31]. The very significant chemical and structural changes in the solid mineral phase are primarily a function of "crystal age" and clearly directly related to the very rapid local turnover of bone substance and its crystals, in many instances over widely separated local regions of a particular bone.

Other difficulties in accurately determining the chemical composition and structure of the bone mineral at any one point of time in a specific location of a particular bone during it's initial formation and subsequent maturation (as a function of age of the animal and especially "crystal age") are also due to the very complex internal geometric disposition of the bone substance containing the crystals at all levels of the anatomical hierarchy, observable from light microscopy to high resolution transmission electron microscopy and atomic force microscopy. For example, it is clear from light microscopy and contact X-ray microscopy that there are great differences in the mineral content of individual, immediately adjacent osteons, for example, and in immediately adjacent individual lamellae of a single osteon. Indeed, transmission electron microscopy and electron diffractometry, and other high resolution techniques, have highlighted the compositional, structural and mineral content differences of the bone mineral substance due to the marked heterogeneity within various volumes of the bone substance at all anatomic levels observable from light microscopy to high resolution TEM, atomic force microscopy, and even higher levels of resolution.

It was also clear from the early TEM experiments that the exposure of samples of bone to water introduced significant dissolution of the bone nanocrystals as well as phase and compositional changes in many of the remaining crystals in the samples of bone. It was therefore clear that the preparation of samples of bone for microscopy at all levels of resolution, and their chemical and physical properties would all require the preparation and analyses of samples of bone without exposure to water.

The earliest such experiments were carried out on the very outermost layers of bone of the midshaft of the long bones of embryonic chick (and other species) using only non-aqueous solvents. The bone samples were powdered and density separated in non-aqueous solvents. 
The very lowest density fractions were first evaluated by wide angle X-ray diffraction, chemical composition and ${ }^{31} \mathrm{P}$ NMR, revealing the presence of only very poorly crystallized apatite. There was no evidence of an initially "amorphous Ca-P solid phase" which had first been postulated by Posner et al, which, with time (higher density samples), underwent either a solid state phase change to very poorly crystallized apatite crystals or was first solubilized and then recrystallized as poorly crystallized apatite crystals [32-36].

Further compositional and structural studies to ascertain the structure of the initially nucleated bone crystals were carried out on the intramuscular bones of various species of fish. The use of these bones containing highly oriented collagen fibrils provide many important advantages in identifying the location and nature of the first $\mathrm{Ca}-\mathrm{P}$ solid phase formed very accurately at high resolution. Using high definition synchrotron-generated X-ray diffraction and FTIR, and the simultaneous measurement of the concentrations of calcium and inorganic phosphorus at the same sites [37] clearly established that the earliest $\mathrm{Ca}-\mathrm{P}$ solid phase deposited during the calcification of the fish bones is a very poorly crystalline solid phase of apatite, similar to the results obtained from the earliest detectable $\mathrm{Ca}-\mathrm{P}$ mineral phase found in chick and other species. Note that the earliest solid $\mathrm{Ca}-\mathrm{P}$ mineral phase in the fish bones was obtained from freshly caught fish immediately frozen while alive in liquid nitrogen and examined using a temperature-cooled stage.

\section{The location of the nanocrystals of bone mineral in bone substance}

A good deal of attention has also been focused more exactly on where the nanocrystals are located in the bone substance as a function of time, the varying distribution of the crystals within the collagen fibrils, and their effect on the biological and mechanical properties of the different locations within the collagen fibrils as a function of time. First, essentially, all of the bone crystals are formed within the collagen fibrils, initially at specific repeating locations along the approximately $670 \AA$ longitudinal repeat period of the individual collagen fibrils. The process of initiating the formation of the crystals is now universally accepted to be initiated by a process of heterogeneous nucleation $[21,22,23]$. Continued nucleation of more crystals and the growth of the previously deposited crystals eventually occupy "all" of the free space within the bone collagen fibrils. This essentially converts bone substance to a composite structural material with important and changing critical physiological functions and with changing mechanical, chemical and interaction properties as a function of the changing location(s) of the nanocrystals within the collagen fibrils and the extent of collagen fibril mineralization. For example, we note the frequent misunderstanding of the implications of a substance or material being a "composite." It is not simply that the mechanical, chemical, electrical, etc. properties of the composite material can be markedly altered simply by the addition of the different properties of each of the individual components, but instead by the geometric spatial relationships between the individual layers, for example, and by the nature and strength of the forces and interactions between the individual separate components. Thus one misses the point of constructing a composite material if all one intends to accomplish is to add together the various properties of the individual components of the composite. For example, if one is dealing with bone substance as a composite material, its mechanical properties cannot be attributed solely to the mechanical properties of the individual components of which it is constructed, i.e. that the collagen fibrils contribute the longitudinal tensile strength properties to the composite, the crystals contribute the compression properties, etc. The mechanical properties of the composite are due principally to the spatial relationships between the various layers and the interactive forces between the two (or more) such layers, viz., collagens, mineral crystals, chemical and other forces between the two (or more) components, etc. 


\section{Synthetic calcium phosphate crystals}

What we have tried to emphasize thus far is that despite taking advantage of the expanding technological advances in observing and measuring the properties of the nanocrystals of bone and synthetic apatites, and the theory, practice, and understanding of phase transformations, the myriad of complexities in describing and measuring the composition and structure of the bone mineral and their interaction properties with other components, and the changes in the nanocrystals which occur very rapidly as a function of "crystal age," all of which are dependent on the gross location of the specific bone and microscopic and ultrastructural distribution of the sample to be analyzed, have made it impossible to describe a single chemical composition and structure of the nano sized "bone mineral" crystals, except in very general terms.

For example, one of the main difficulties in correctly describing the chemical composition of bone apatites is due to a lack of very accurate chemical analytic techniques to measure the complicated chemical compositions. For example, the amounts of $\mathrm{HPO}_{4}{ }^{2-}$ and $\mathrm{OH}^{-}$ions in samples of bone apatite cannot be measured by chemical analytic techniques with sufficient accuracy to define their composition. In addition mineralized tissues often contain numerous trace elements which replace other constituents of the bone substance tissue and its crystals [39]. Some of these trace elements are closely related to the solid mineral phase $\left(\mathrm{F}-, \mathrm{Sr}^{2+}\right)$, others are primarily present in the organic matrix ( $\mathrm{Si}, \mathrm{Cu}$ for example) and others such as $\mathrm{Zn}$ may be located in both the solid mineral phase and/or in the organic matrix. Very often, however, such trace elements cannot even be accurately located in specific components in bone substance. Yet another very important difficulty encountered is the presence of a hydrated surface layer of both bone crystals and synthetic apatite crystals which contain varying concentrations of a wide variety of mineral ions [40].

As a result of these difficulties, a number of investigators have directed their research to the properties of synthetic highly crystalline calcium apatites. Indeed some of the most significant progress in understanding important structural and chemical properties of the biological bone apatites (nanocrystals) has been derived from such research on synthetic calcium apatites or in some instances from naturally occurring geological apatites.

It is important to note that the specific physiological, chemical, structural and interactive properties of native bone mineral nanocrystals are not derived from the lattice structure of pure calcium hydroxyapatite, but rather from specific lattice substitutions and ion vacancies [3-6].

\section{Composition of synthetic calcium phosphate apatites}

The composition of synthetic calcium apatites is very complex, and in most cases more complex than in biological apatites, due to multiple lattice substitutions and the presence of varying numbers of ion vacancies [41]. The most relevant of these substitutions in biological apatites are the replacement of the $\mathrm{PO}_{4}{ }^{3}$ anions by bivalent species: $\mathrm{HPO}_{4}{ }^{2-}$ and $\mathrm{CO}_{3}{ }^{-2}$ which have also been detected in large and variable amounts in samples of bone mineral [42-45].

Chemical analyses of synthetic calcium apatites have revealed a common charge compensation mechanism containing these bivalent ions which are created by two ionic vacancies: one of which is on a cationic site and the other on a monovalent anionic site according to the general chemical formula: $\mathrm{Ca}_{10-\mathrm{x}}\left(\mathrm{PO}_{4}\right)_{6-\mathrm{x}}\left(\mathrm{HPO}_{4} \text { or } \mathrm{CO}_{3}\right)_{\mathrm{X}}(\mathrm{OH})_{2-\mathrm{x}}$ [46]. The validity of these charge compensation mechanisms has been recently confirmed by Rietveld analyses of X-ray diffraction patterns of substituted synthetic apatites $[47,48]$. In addition the cationic vacancy has been shown to occur mainly on the Ca (II) site in close proximity to monovalent anionic sites [49], suggesting the existence of clusters of vacancies that are often observed in compounds with a large number of vacancies in accordance with Pauling's rules of the local charge compensation in the lattice (Figure 2). This substitution process explains in part the low 
concentration of $\mathrm{OH}^{-}$ions detected in large synthetic apatites and bone mineral apatites [44]. However, Raman spectroscopy of rat bone indicates only a few percent of the predicted concentration of $\mathrm{OH}^{-}$ions in bone apatites [4]. These studies have indeed provided some of the most significant new information on the possible structure, composition, and reactivity of the nanocrystals of bone mineral derived from research on synthetic calcium apatites. These induced variations in the composition of the apatites occur at all stages of the "age" of the crystals. Although most of the changes are due in large part to multiple ion substitutions and vacancies, an additional phenomenon observed in synthetic apatites, which may also be found in biological apatites, consists of the internal hydrolysis between $\mathrm{PO}_{4}{ }^{3-}$ ions and water molecules in the solid phase $[2,38,39]$ :

$$
\mathrm{PO}_{4}^{3-}+\mathrm{H}_{2} \mathrm{O} \rightarrow \mathrm{HPO}_{4}^{2-}+\mathrm{OH}^{-}
$$

This reaction has also been found to occur in synthetic amorphous calcium phosphate (ACP) [12] and octacalcium phosphate (OCP) [13] and could be present in non-stoichiometric apatites. It would be limited, however, by the number of $\mathrm{OH}^{-}$vacancies, leading to the following chemical formula:

$$
\mathrm{Ca}_{10-\mathrm{x}}\left(\mathrm{PO}_{4}\right)_{6-\mathrm{x}-\mathrm{y}}\left(\mathrm{HPO}_{4}\right)_{\mathrm{x}+\mathrm{y}}(\mathrm{OH})_{2-\mathrm{x}+\mathrm{y}} .
$$

\section{Non-apatitic environments in bone mineral}

Spectroscopic studies of bone mineral have not only detected the presence of the components of apatite, but also the existence of mineral ions in non-apatitic arrays [50-53]. Spectroscopic studies of synthetic nanocrystalline calcium apatites have shown that these ions are also located in a hydrated layer on the surfaces of the crystals [54]. The surface hydrated layer of synthetic apatite nanocrystals contains mainly bivalent ions, a large proportion of which are $\mathrm{CO}_{3}{ }^{2-}$ and $\mathrm{HPO}_{4}{ }^{2-}$ ions (Figure 3). However, carbonate and $\mathrm{HPO}_{4}{ }^{2-}$ ions have also been found in apatitic domains. These findings make it necessary to revise the chemical composition of bone apatite crystals based on well-crystallized, large non-stoichiometric synthetic apatites which do not include the composition of their hydrated surface layer. Interesting data obtained by NMR of synthetic apatites [55] suggest that as much as 55\% of the total inorganic phosphate ions reside on a disturbed surface layer of synthetic apatite nanocrystals.

Little is known about the structure of this hydrated layer on the surface of synthetic calcium apatites. Additional spectroscopic analyses of wet samples of synthetic calcium apatite crystals have shown that the hydrated surface produces narrow but specific spectroscopic bands depending on its composition [56]. For example, importantly, the FTIR spectra of wet $\mathrm{HPO}_{4}{ }^{2}$ containing synthetic nanocrystals have been found to be very similar but not identical to OCP, while ${ }^{31} \mathrm{P}$-solid state NMR spectra are very different from those of octacalcium phosphate which contain $\mathrm{HPO}_{4}{ }^{2-}$ environments very similar to those of dicalcium phosphate dihydrate (DCPD) [56].

These data illustrate the difficulty of identifying even the non-apatitic environments of synthetic Ca-P apatites. Moreover, the differences found depend on the techniques used to examine these environments. Importantly, the spectroscopic data of synthetic apatites have also been shown to be very sensitive to partial and complete drying. For example, the spectroscopic peaks are not completely preserved in dry samples which exhibit only a single broad spectroscopic band of an amorphous-like mineral phase [56]. Furthermore, depending 
on the experimental conditions, the non-apatitic structure in the same sample has been identified as DCPD using solid state NMR, OCP by FTIR, and ACP in fully dried samples!

From similar experiments, investigators also concluded that a DCPD-like structure was also present based on ${ }^{31} \mathrm{P}$-solid state NMR of bone [49] although XRD and electron diffraction failed to detect a separate DCPD phase. More recent solid state NMR studies on completely dried bone samples have given more ambiguous results: the presence of $\mathrm{HPO}_{4}{ }^{2-}$ ions which exhibit a chemical shift of $\mathrm{HPO}_{4}{ }^{2-}$ species very similar to that of OCP but a chemical shift anisotropy closer to that of DCPD! [7].

It is very interesting that studies of biological mineralization of invertebrates have in many ways paralleled those in bone and other vertebrate tissues in most instances, but differ significantly in many aspects. Importantly, the tissues are mineralized by the deposition of a solid phase of $\mathrm{CaCO}_{3}$ [57], and not by crystals of calcium phosphate [58-61]. Weiner's group has contributed a very significant number of important original contributions in this field, clearly demonstrating that the initial solid phase of $\mathrm{CaCO}_{3}$ deposited in these tissues is an amorphous solid phase which later undergoes a solid phase transition to large, highly crystalline $\mathrm{CaCO}_{3}$ (calcite or aragonite), or was solubilized and re-crystallized as highly crystalline calcite or aragonite. However, whether or not these data of an initial "precursor" phase of $\mathrm{CaCO}_{3}$ that is first deposited in the tissue and later converts to highly crystalline calcite or aragonite, it does not necessarily follow that this same sequence occurs in all biologically mineralized tissues. The theory that a solid amorphous "precursor" mineral phase is formed prior to the formation of a crystalline mineral phase [34] has not been substantiated in bone [62].

For example, we have already presented the data, some of which appears in this contribution, which demonstrated that we were unable to detect the presence of a precursor amorphous solid Ca-P phase in bone prepared anhydrously and analyzed by scanning the entire length of the long thin bone(s) by synchrotron-generated X-ray diffraction until the very first small region of the bone which first generates a wide angle $\mathrm{X}$-ray diffraction pattern was found. This region is then bracketed and the leading edge of the region once again analyzed by synchrotrongenerated wide angle X-ray diffraction. This was repeated until there was only a barely visible diffraction pattern. The $\mathrm{X}$-ray apparatus was then focused a very small distance away from the faint $\mathrm{X}$-ray diffraction reflections and the tissue exposed to further wide-angle $\mathrm{X}$-ray diffraction for a much larger period. The X-ray diffraction pattern clearly identified very poorly crystalline apatite. The sequence was again repeated and similarly identified as poorly crystalline apatite. No evidence was obtained for the presence of any other phase of Ca-P crystals.

\section{Precursor Phase(s) of Apatitic Nanocrystals}

A recent paper concerning possible Ca-P "precursor phases" formed prior to the formation of poorly crystalline calcium- phosphate apatites in bone has been published [64]. In these experiments, the authors utilized an ingenious and very clever experimental protocol using newly synthesized living intramembranous cranial bone in the suture lines and analyzed the tissue by Raman microspectroscopy. The authors identified several distinct "transient" Ca-P solid phases of octacalcium phosphate (OCP) or "OCP-like solid phases" as well as other components such as an amorphous calcium phosphate (ACP) solid phase. These early solid phases of $\mathrm{Ca}-\mathrm{P}$ contain large numbers of carbonate ions in non-apatitic environments. The existence of carbonate ions in OCP is not compatible with the identification of such $\mathrm{Ca}-\mathrm{P}$ mineral crystals containing OCP since no carbonate containing OCP crystals or other nonapatite crystalline phases containing carbonates have hitherto been identified [40].

Also, there is no explanation for the presence of OCP or an "OCP-like" solid phase by spectroscopy of so-called "precursor" phases different from apatites if one utilizes only one particular ion compound to identify the solid phase. For example, similar analyses of the FTIR- 
$\mathrm{PO}_{4}$ bands of apatite nanocrystals and those of OCP, which, when present can be definitely identified by the most specific spectroscopic band of phosphate ions at $915 \mathrm{~cm}^{-1}$ and which has never been detected in samples of bone or in the mineral phase formed in vivo during the stimulation of new bone in the intracranial substance [65]. We do not feel that the conclusion that OCP or "OCP-like" crystals exist in bone as distinct crystalline phases and can account for the very large number of non-apatite environments found in newly formed bone mineral at any stage of new bone formation.

As already mentioned, the earliest formed crystals are very unstable and readily transformed to other phases such as OCP or, DCPD after short exposures to water. In this instance we note that OCP and "OCP-like" solid phases and other solid Ca-P solid phases were also subjected to exposure to water during the formative period and again before and during the spectroscopies - ample time to convert young newly formed Ca-P phases to OCP or "OCP-like" crystals and ACP, etc. [41].

The publication of the paper by Crane et al [65] elicited several sharp responses. Weiner [63] commented that at long last experimental evidence had finally been obtained that the initial solid phase of $\mathrm{Ca}-\mathrm{P}$ formed during the calcification of bone was not a poorly crystalline apatite but, rather, like the calcification of invertebrate shells by $\mathrm{CaCO}_{3}$, the initial solid phase of $\mathrm{Ca}-$ $\mathrm{P}$ formed in bone was an amorphous $\mathrm{Ca}-\mathrm{P}$, only later replaced by poorly crystalline apatite. Unfortunately, the Raman spectroscopy data obtained by Crane et al [65] actually showed that the major $\mathrm{Ca}-\mathrm{P}$ solid phases first detected were OCP or "OCP-like" "crystals," as well as "other" minor unidentified Ca-P solid phases such as amorphous Ca-P (ACP).

A reply [64] to the original publication by Crane et al [65] and to the editorial by Weiner [63] was critical of both the original publication [65] and Weiner's editorial [63]. The authors of the present paper also have some serious misgivings about the interpretations of Crane et al [65], and our admonitions that one is dealing with the formation of a solid phase consisting of only a very small number of ions (nanocrystals) whose interaction properties are, importantly, distinct from those of classical, physical chemistry of large-sized crystals [31].

No X-ray, electron, or neutron diffraction evidence has ever reproducibly provided data supporting this hypothesis presented by Crane et al [65]. In addition, a careful examination of spectroscopic data obtained by different techniques and an exploration of all spectroscopic characteristics (not only special features) does not support the existence of separate crystalline phases different from those of apatite, even in the youngest samples of bone from the youngest animals. For example, despite some analogy between the FTIR $\mathrm{PO}_{4}$ bands of apatite nanocrystals and that of OCP, the most specific FTIR band of OCP at $915 \mathrm{~cm}^{-1}$ has never been detected in such samples of bone [56]. We conclude that OCP as a distinct crystalline phase has not been detected in bone. Also, no spatially specific phase other than apatite can account for the very large quantity of non-apatitic environments found in bone mineral. In addition, the initially formed apatite nanocrystals of bone mineral are very unstable, especially when first formed in embryonic bone, and can readily undergo a phase transition in the presence of water to other phases such as OCP and DCPD, which have occasionally been identified [66]. Another aspect to consider is the presence of large amounts of carbonate ions in non-apatitic environments. As already noted, these ions are not compatible with the formation of OCP crystals, and to date, no carbonate-containing OCP crystals or other non-apatitic phases have been detected. The existence of these ions is not compatible with the formation of OCP crystals, and to date, no carbonate-containing OCP crystals or other non-apatitic phases have been detected. Regarding the reactivity of nanocrystalline apatites, especially as it relates to nonapatitic environments, it also differs remarkably from OCP in its very large capacity for ion exchange: calcium can be replaced by magnesium (up to $8.5 \%$ ) or strontium (up to $20 \%$ ) and $\mathrm{HPO}_{4}{ }^{2-}$ ions can be exchanged by carbonate (up to $44 \%$ ) with minor changes in the X-ray 
diffraction patterns and its crystal appearance $[67,68]$. We conclude that the non-apatitic environments detected by spectroscopic methods should not be confused with the existence of precursor crystalline phases different from those of apatite, especially when only one type of ion is considered.

However, a recent publication has reported that a solid amorphous Ca-P phase is a major component in the forming fin bones of Zebra fish, and may be a precursor Ca-P mineral phase that later "transforms" into mature crystalline CA-P apatite [69]. We have previously published extensive studies of the intramuscular bones of several species of fish by high resolution synchrotron X-Ray diffraction, FTIR, and other techniques to determine the nature of the Ca$\mathrm{P}$ deposited, viz., starting from the unmineralized portion of the thin long fish bones to the junction of the uncalcified portion of the bone and the first detection of Ca-P mineral. The intramuscular bones were obtained from freshly caught live fish, which were immediately frozen alive in liquid nitrogen, and the dissected bones analyzed on cold stages. The first evidence obtained of the presence of the solid CA-P deposit were definitively identified as very poorly crystalline $\mathrm{Ca}-\mathrm{P}$ apatite. There was no evidence of an amorphous calcium phosphate solid phase.

We also note the following reservations we have about the conclusions reached by Mahamid et al [69]: the FTIR band at $961 \mathrm{~cm}^{-1}$ is characteristic of apatite and not carbonated apatite; this band is also due to $\mathrm{HPO}_{4}{ }^{2-}$ or carbonate-containing apatite. Amorphous Ca-P generally generates a broad band at $950\left(10 \mathrm{~cm}^{-1}\right)$ lower than apatite. It is not present in the FTIR spectrum presented by Mahamid et al [69]. It is sometimes very difficult to record this spectrum and may require further deconvolution or decomposition of the FTIR data to detect it.

Another major issue involves the use of sodium hypochlorite which is very prone to cause precipitation of an amorphous Ca-P solid phase. This can easily be demonstrated by adding sodium hypochlorite to serum or plasma.

\section{Acknowledgments}

We gratefully acknowledge the help of Phillips Brady and other members of the Massachusetts Department of Fisheries, which enabled us to obtain large numbers of live fish. The research projects were supported by grants from NIH (Grant No. AG0 14701-18) (Melvin Glimcher) and The Peabody Foundation (Melvin Glimcher).

\section{References}

1. de Jong WF. La substance minerale dans les os. Recl Trav Chim Pays - Bas Belg 1926;45:445-448.

2. Roseberry HH, Hastings AB, Morse JK. X-ray analysis of bone and teeth. J Biol Chem 1931;90:395407.

3. Rey C, Miquel J, Facchini L, Legrand A, et al. Hydroxyl groups in bone mineral. Bone 1995;16:583586. [PubMed: 7654473]

4. Pasteris JD, Wopenka B, Freeman JJ, et al. Lack of $\mathrm{OH}$ in nanocrystalline apatite as a function of degree of atomic order: implications for bone and biomaterials. Biomaterials 2004;25:229-238. [PubMed: 14585710]

5. Loong CK, Rey C, Kuhn LT, et al. Evidence of hydroxyl-ion deficiency in bone apatites: an inelastic neutron-scattering study. Bone 2000;26:599-602. [PubMed: 10831931]

6. Wu Y, Ackerman JL, Kim H-M, et al. Nuclear magnetic resonance spin-spin relaxation of the crystals of bone, dental enamel and synthetic hydroxyapatite. J Bone Miner Res 2002;17:472-480. [PubMed: 11874238]

7. Wu Y, Glimcher MJ, Rey C, et al. A unique protonated phosphate group in bone mineral and not present in synthetic calcium phosphates. Identification by phosphorus-31 solid state NMR spectroscopy. J Mol Biol 1994;244:423-435. [PubMed: 7990131]

8. Stuhler R. Fortschr Gebiete Rontgenstrahlen. 1938;57:231. 
9. Robinson RA. An electron microscopic study of the crystalline inorganic components of bone and its relationship to the organic matrix. J Bone Joint Surg 1952;34:389-476. [PubMed: 14917711]

10. Robinson RA, Watson ML. Collagen-crystal relationships in bone as seen in the electron microscope. Anat Rec 1953;114:383-409. [PubMed: 12996880]

11. Robinson RA, Watson ML. Crystal-collagen relationships in bone as observed in the electron microscope. III. Crystal and collagen morphology as a function of age. Ann NY Acad Sci 1955;60:596-628. [PubMed: 14377302]

12. Engstrom A, Finean JB. Low-angle X-ray diffraction of bone. Nature 1953;171:564. [PubMed: 13054624]

13. Finean JB, Engstrom A. The low-angle scatter of X-rays from bone tissue. Biochim Biophys Acta 1953;11:178-189. [PubMed: 13081589]

14. Finean JB, Engstrom A. Low-angle reflection in X-ray diffraction patterns of bone tissue. Experientia 1954;10:63-64. [PubMed: 13151169]

15. Carlstrom D, Finean J. X-ray diffraction studies on the ultrastructure of bone. Biochim Biophys Acta 1954;13:183-191. [PubMed: 13140313]

16. Bocciarelli DS. Apatite microcrystals in bone and dentin. J Microsc 1973;16:21-34.

17. Bocciarelli DS. Morphology of crystallites in bone. Calcif Tissue Res 1970;5:261-69. [PubMed: 5433628]

18. Kim HM, Rey C, Glimcher MJ. Isolation of calcium-phosphate crystals of bone by non-aqueous methods at low temperature. J Bone Miner Res 1995;10:1589-1601. [PubMed: 8686516]

19. Tong W, Glimcher MJ, Katz, et al. Size and shape of mineralities in young bovine bone measured by atomic force microscopy. Calcif Tissue Int 2003;72:592-598. [PubMed: 12724830]

20. Eppell SJ, Tong W, Katz JL, et al. Shape and size of isolated bone mineralites measured using atomic force microscopy. J Orthop Res 2001;19:1027-1034. [PubMed: 11781001]

21. Rey C, Miquel JL, Facchini L, et al. Hydroxyl groups in bone mineral. Bone 1995;16(5):583-86. [PubMed: 7654473]

22. Glimcher MJ, Hodge AJ, Schmitt FO. Macromolecular aggregation states in relation to mineralization: the collagen hydroxyapatite system as studied in vitro. Proc Natl Acad Sci USA 1957;43:860-867. [PubMed: 16590100]

23. Glimcher MJ. Molecular biology of mineralized tissues with particular reference to bone. Rev Mod Phys 1959;31:359-393.

24. Glimcher, MJ. Specificity of the molecular structure of organic matrices in mineralization. In: Sognnaes, RF., editor. Calcification in Biological Systems. American Association for the Advancement of Science; Washington, DC: 1960. p. 421-487.

25. Chen J, Burger C, Krishnan CV, et al. In vitro mineralization of collagen in demineralized fish bone. Macromol Chem Phys 2005;206:43-51.

26. Katz EP. The kinetics of mineralization in vitro. Biochim Biophys Acta 1969;194:121-129. [PubMed: 5389443]

27. Wang J, Zhou HY, Salih E, et al. Bone sialoprotein elicits mineralization and ossification in a bone defect model. 2004Sodek, J.; Landis, W., editors. Proceedings of 8th International Conference on Chemistry and Biology of Mineralized Tissue; Oct 17-24, 2004; Banff, Alberta, Canada. Toronto: University of Toronto Press; 2005. p. 139-142.

28. Wang J, Zhou HY, Salih E, et al. Site-specific in vivo calcification and osteogenesis stimulated by bone sialoprotein. Calcif Tissue Int 2006;79:179-189. [PubMed: 16969594]

29. Tye, Ce; Rattray, KR.; Warner, KJ., et al. Delineation of the hydroxyapatite-nucleating domains of bone sialoprotein. J Biol Chem 2003;278:7949-7955. [PubMed: 12493752]

30. Wu Y, Ackerman JL, Strawich ES, et al. Phosphate ions in bone: identification of a calcium-organic phosphate complex by ${ }^{31} \mathrm{P}$ solid-state NMR spectroscopy at early stages of mineralization. Calcif Tissue Int 2003;72:610-26. [PubMed: 12724829]

31. Glimcher, MJ. Bone: Nature of the calcium phosphate crystals and cellular, structural, and physical chemical mechanisms in their formation. In: Sahai, N.; Schoonen, MAA., editors. Medical Mineralogy and Geochemistry. Vol. 64. The Mineralogical Society of America; Chantilly, Virginia: 2006. p. 223-282. 
32. Eanes, ED.; Harper, RA.; Gillessen, IH., et al. An amorphous component in bone mineral. In: Galliard, PJ.; van der Hoff, A.; Steendyk, R., editors. Proceedings of $4^{\text {th }}$ European Symposium on Calcified Tissues. Amsterdam: Excerpta Medica, Amsterdam; 1966. p. 24-26.

33. Termine JD, Posner AS. Infrared analysis of rat bone: age dependency of amorphous and crystalline mineral fractions. Science 1967;153:1523-1525. [PubMed: 5917783]

34. Blumenthal N, Posner A. Hydroxyapatite: mechanism of formation and properties. Calcif Tissue Int 1973;13:235-243.

35. Posner A, Betts F. Synthetic amorphous calcium phosphate and its relation to bone mineral. Acc Chem Res 1975;8:273-281.

36. Boskey AL, Posner AS. Extraction of a calcium-phosphate complex from bone. Calcif Tissue Res 1976;19:273-283. [PubMed: 3268]

37. Glimcher, M.; Hanson, J.; Hori, et al. Structural Analysis of the earliest Ca-P solid phase in Bone measured in situ. Referred manuscript published in proceedings of the 8th ICCBMT; Banff, Alberta, Canada. Oct. 17-22, 2004; 2004. p. 254

38. Heughebaert JC, Montel G. Conversion of amorphous tricalcium phosphate into apatitic tricalcium phosphate. Calif Tissue Int 1982;34:S103-S108.

39. Mathew M, Brown WE, Schroeder LW. Crystal structure of octacalcium bis-(hydrogenphosphate) tetrakis(phosphate)-pentahydrate, $\mathrm{Ca}_{8}\left(\mathrm{HPO}_{4}\right)_{2}\left(\mathrm{PO}_{4}\right)_{4} 5 \mathrm{H}_{2} \mathrm{O}$. J Cryst Spec Res 1988;18:235-250.

40. Lyengar, GV.; Tandon, L. Minor and trace elements in human bones and teeth. International Atomic Energy Agency; Vienna: 1999. NAHRES-39 report

41. Neuman, WF.; Neuman, MW. The Chemical Dynamics of Bone Mineral. University of Chicago Press; Chicago: 1958.

42. Elliott, JC. Structure and Chemistry of the Apatites and Other Calcium Orthophosphates. Elsevier; Amserdam: 1994.

43. Pellegrino ED, Blitz RM. Mineralization in the chick embryo. I. Monohydrogen phosphate and carbonate relationships during maturation of the bone crystal complex. Calif Tissue Res 1972;10:128-135.

44. Biltz RM, Pellegrino ED. The nature of bone carbonate. Clin Orthop 1977;129:279-292. [PubMed: 608288]

45. Legeros, RZ. Biological and synthetic apatites. In: Brown, PW.; Constanz, B., editors. Hydroxyapatite and Related Materials. CRC Press; Boca Raton, Florida: 1994. p. 3-28.

46. Legeros R, Balmain N, Bonel G. Age-related changes in mineral of rat and bovine cortical bone. Calcif Tissue Int 1987;41:137-144. [PubMed: 3117340]

47. Wilson RM, Elliott JC, Dowker SEP, et al. Rietveld refinements and spectroscopic studies of the structure of Ca-deficient apatite. Biomaterials 2005;26:1317-1327. [PubMed: 15475062]

48. Wilson RM, Dowker SEP, Elliott JC. Rietveld refinements and spectroscopic structural studies of a Na-free carbonate apatite made by hydrolysis of monetite. Biomaterials 2005;27:4682-4692. [PubMed: 16750850]

49. Labarthe JC, Bonel G, Montel G. Structure and properties of B-type phosphocalcium carbonate apatites. Annales de Chimie (Fr) 1973;8:289-301.

50. Roufosse AH, Aue WP, Roberts JE, et al. Investigation of the mineral phases of bone by solid state phosphorus-31 magic angle spinning nuclear magnetic resonance. Biochem 1984;23:6115-6120. [PubMed: 6525350]

51. Rey C, Collins B, Goehl T, et al. The carbonate environment in bone mineral. A resolution enhanced Fourier transform infrared spectroscopy study. Calcif Tissue Int 1989;45:157-164. [PubMed: 2505907]

52. Rey C, Shimkizu M, Collins B, et al. Resolution enhanced Fourier transform infrared spectroscopic study of the environment of phosphate ion in the early deposits of a solid phase of calcium phosphate in bone and enamel and their evolution with age. I. Investigation in the $\mathrm{v}_{4} \mathrm{PO}_{4}$ domain. Calcif Tissue Int 1990;46:384-394. [PubMed: 2364326]

53. Lu HB, Campbell CT, Graham DJ, et al. Surface characterization of hydroxyapatite and related calcium phosphates by XPS and TOF-SIMS. Anal Chem 2000;72:2886-2894. [PubMed: 10905323] 
54. Eichert, D.; Drouet, C.; Sfihi, H., et al. Nanocrystalline apatite-based biomaterials: synthesis, processing and characterization. Kendall, JB., editor. Biomaterials Research Advances; Nova: 2007. p. 93-143.

55. Jager C, Welzel T, Meyer-Zaika W, et al. A solid state NMR investigation of the structure of nanocrystalline hydroxyaptite. Magn Reson Chem 2006;44:573-580. [PubMed: 16395729]

56. Eichert D, Sfihi H, Combes C, et al. Specific characteristics of wet nanocrystalline apatites: consequences on biomaterials and bone tissue. Key Eng Mater 2004;254-256:927-930.

57. Towe KM, Lowenstam HA. Ultrastructure and development of iron mineralization in the radular teeth of Cryprochiton stelleri (Mollusca). J Ultrastruc Res 1967;17:1-13.

58. Lowenstam HA, Weiner S. Transformation of amorphous calcium phosphate to crystalline dahllite in the radular teeth of chitons. Science 1985;227:51-53. [PubMed: 17810022]

59. Aizenberg J, Lambert G, Weiner S, et al. Factors involved in the formation of amorphous and crystalline calcium carbonate: a study of an ascidian skeleton. J Am Chem Soc 2002;124:32-39. [PubMed: 11772059]

60. Aizenberg J, Weiner S, Addadi L. Coexistence of amorphous and crystalline calcium carbonate in skeletal tissues. Connect Tissue Res 2003;44(Supp 1):20-25. [PubMed: 12952169]

61. Weiner S, Levi-Kalisman Y, Raz S, et al. Biologically formed amorphous calcium carbonate. Connect Tissue Res 2003;44(Supp 1):214-218. [PubMed: 12952200]

62. Weiner S, Sagi I, Addadi L. Choosing the crystallization path less traveled. Science 2005;29:10271028. [PubMed: 16099970]

63. Weiner S. Transient precursor strategy in mineral formation of bone. Bone 2006;39:431-433. [PubMed: 16581322]

64. Grynpas MD, Omelon S. Transient precursor strategy or very small apatite crystals? Bone 2007;41:162-164. [PubMed: 17537689]

65. Crane NJ, Popescu V, Morris MD. Raman spectroscopic evidence for octacalcium phosphate and other transient mineral species deposited during intramembranous mineralization. Bone 2006;39:434-442. [PubMed: 16627026]

66. Muenzenberg KG, Gebhardt M. Brushite, octacalcium phosphate, and carbonate-containing apatite in bone. Clin Orthop Rel Res 1973;90:271-273.

67. Cazalbous, S. PhD thesis. INPT; France: 2000.

68. Eichert, D. PhD thesis. INPT; France: 2001.

69. Mahamid J, Sharir A, Addadi L, Weiner S. Amorphous calcium phosphate is a major component of the forming fin bones of zebrafish: Indications for an amorphous precursor phase. Proc Nat Acad Sci 2008;105:12748-12753. [PubMed: 18753619] 

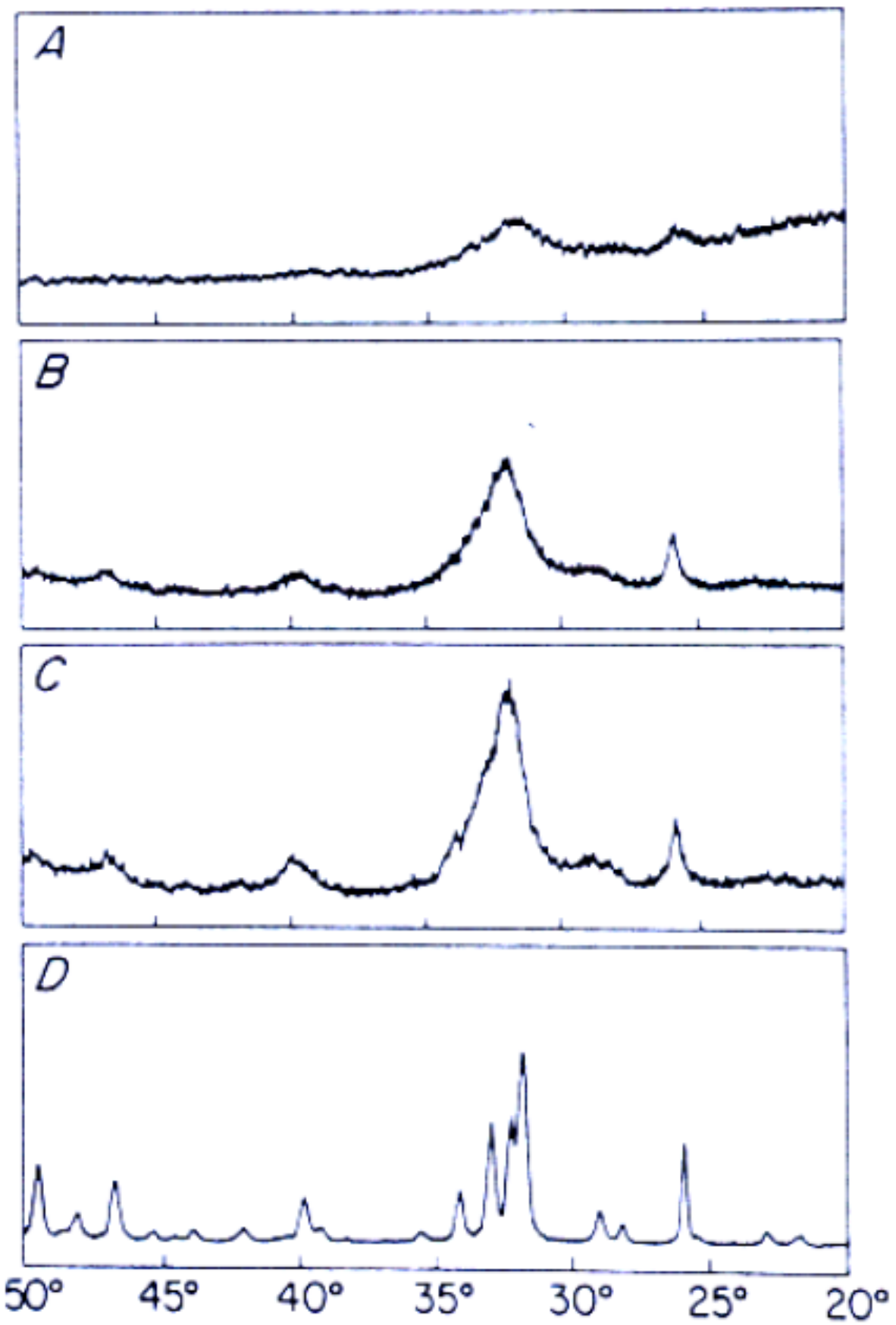

Figure 1.

$\mathrm{X}$-ray diffractometer patterns obtained from bone fractions with intensity as the ordinate and

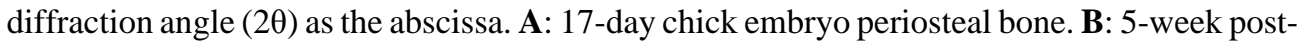
hatch chick, 2.1-2.2 g/ $\mathrm{cm}^{3}$ density fraction. C: 2 -year-old chick, 2.2-2.3 g/ $/ \mathrm{cm}^{3}$ density fraction. D: highly crystalline synthetic hydroxyapatite. Patterns derived from rate meter charts obtained with a continuously scanning diffractometer equipped with a diffracted-beam monochromator, using $\mathrm{CuK} \alpha$ radiation. 


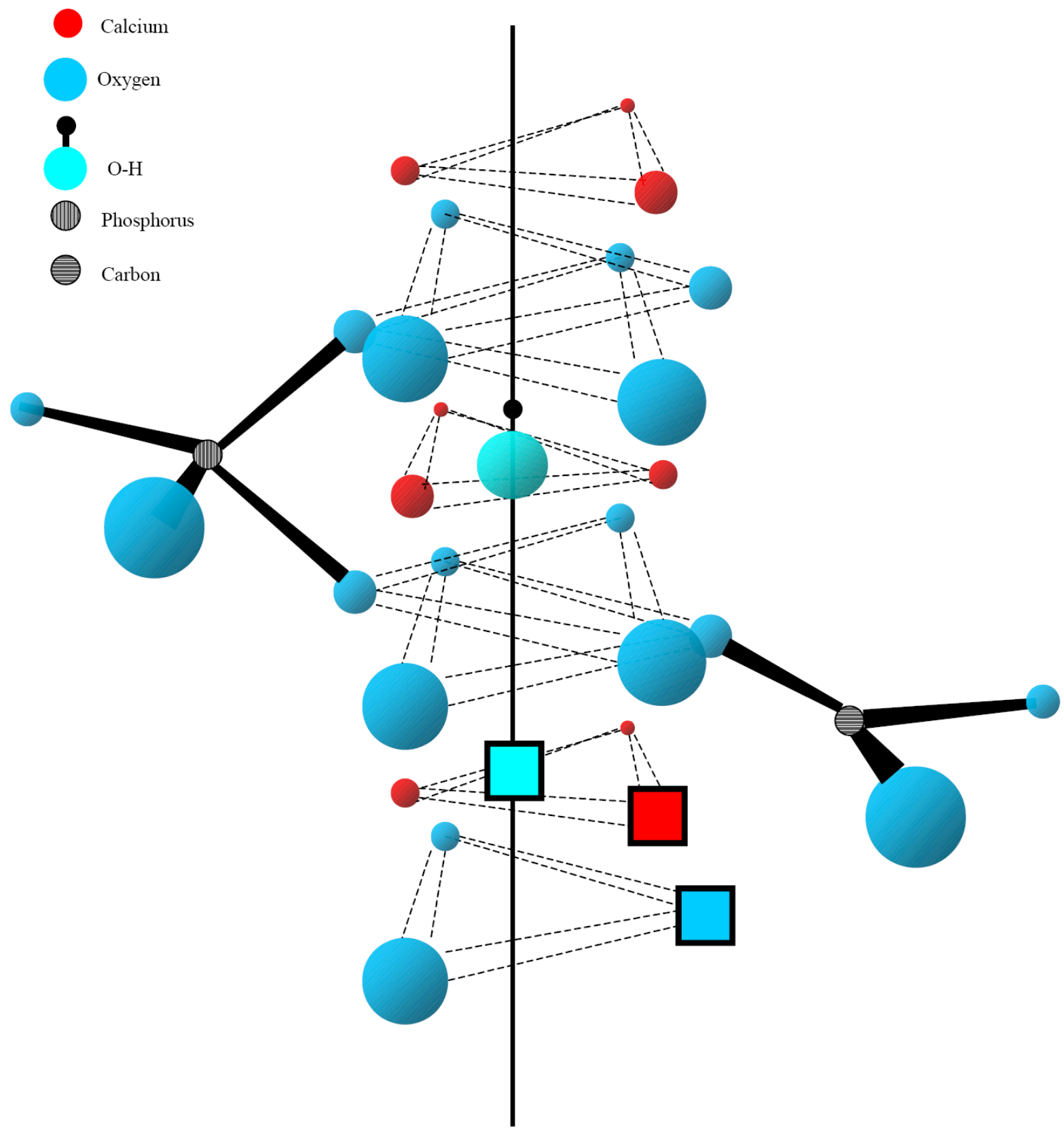

Figure 2.

Charge compensation mechanism in type $\mathrm{B}$ carbonate- and $\mathrm{HPO}_{4}{ }^{2-}$-containing apatites explaining the $\mathrm{OH}^{-}$deficit. The replacement of a $\mathrm{PO}_{4}{ }^{3-}$ ions by bivalent species is associated with a cationic vacancy in $\mathrm{Ca}^{2+}$ sites (type II) and a vacancy in the monovalent $\mathrm{OH}^{-}$site (according to Labarthe et al.[49]). 


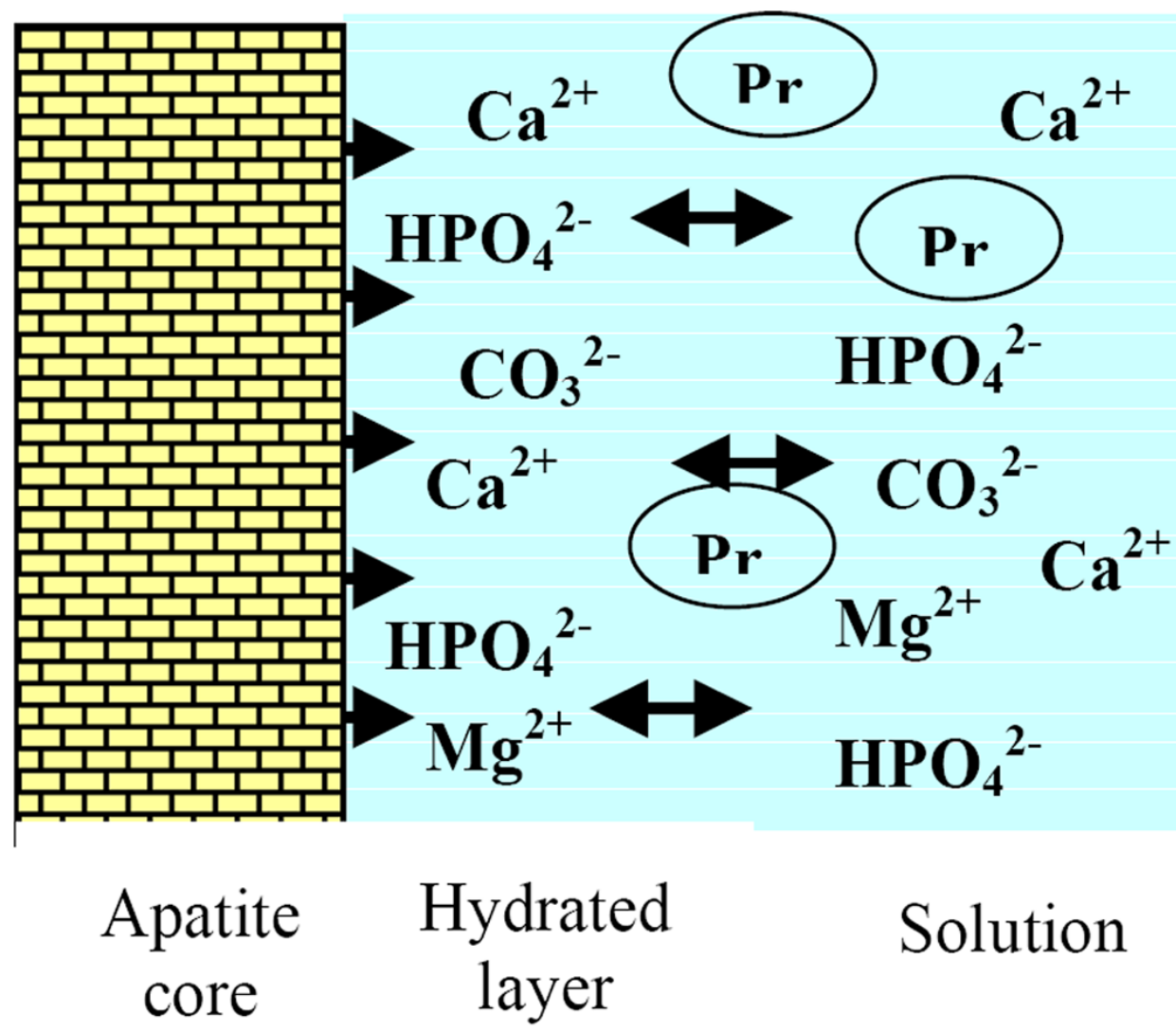

Figure 3.

Schematisation of apatite nanocrystals of bone mineral. The core of the crystals is a nonstoichiometric apatite lattice. At the surface a structured hydrated layer contains loosely bound ions which can be incorporated in the growing and more stable apatite domains (arrows). The ions of the hydrated layer can be easily and reversibly exchanged by ions of the surrounding fluids or charged groups of proteins $(\operatorname{Pr})$ determining the surface reactivity and surface interactions involving the nanocrystals. 